\title{
PRODUCT QUALITY AND FIRM HETEROGENEITY \\ IN INTERNATIONAL TRADE
}

\author{
by \\ Antoine Gervais \\ University of Notre Dame
}

\begin{abstract}
CES 13-08 March, 2013
The research program of the Center for Economic Studies (CES) produces a wide range of economic analyses to improve the statistical programs of the U.S. Census Bureau. Many of these analyses take the form of CES research papers. The papers have not undergone the review accorded Census Bureau publications and no endorsement should be inferred. Any opinions and conclusions expressed herein are those of the author(s) and do not necessarily represent the views of the U.S. Census Bureau. All results have been reviewed to ensure that no confidential information is disclosed. Republication in whole or part must be cleared with the authors.

To obtain information about the series, see www.census.gov/ces or contact Fariha Kamal, Editor, Discussion Papers, U.S. Census Bureau, Center for Economic Studies 2K132B, 4600 Silver Hill Road, Washington, DC 20233, CES.Papers.List@census.gov.
\end{abstract}




\begin{abstract}
I develop and implement a methodology for obtaining plant-level estimates of product quality from revenue and physical output data. Intuitively, firms that sell large quantities of output conditional on price are classified as high quality producers. I use this method to decompose cross-plant variation in price and export status into a quality and an efficiency margin. The empirical results show that prices are increasing in quality and decreasing in efficiency. However, selection into exporting is driven mainly by quality. The finding that changes in quality and efficiency have different impact on the firm's export decision is shown to be inconsistent with the traditional iceberg trade cost formulation and points to the importance of per unit transport costs. ${ }^{\mathrm{i}}$
\end{abstract}

Keywords: Firm heterogeneity, microdata, quality, trade, unit value. JEL Classification Numbers: F1

${ }^{\mathrm{i}}$ I am grateful to Nuno Limao, John Haltiwanger, and John Shea for their invaluable guidance throughout the completion of this project. I also thank Andrew Bernard, Jeffrey Bergstrand, J. Bradford Jensen, Joseph Kaboski, Peter Schott and seminar and conference participants at Brandeis University, Georgetown, George Washington, HEC Montreal, Queen's, UBC, Wisconsin, Yale, North American Summer Meetings of the Econometric Society (2009), Meeting of the Midwest Economics Association (2009), U.S Census Center for Economic Studies for their comments. The research in this paper was conducted while the author was Special Sworn Status researcher of the U.S. Census Bureau at the Center for Economic Studies Research Data Center in Washington DC. Results and conclusions expressed are those of the author and do not necessarily reflect the views of the Census Bureau. The results presented in this paper have been screened to ensure that no confidential data are revealed. All remaining errors are my own. 


\section{INTRODUCTION}

Recent empirical studies point to the importance of product quality differentiation in explaining features of international trade flows. ${ }^{1}$ Unfortunately, we know very little about the extent of quality variation across firms and how it influences firm decisions such as pricing and exporting. An important challenge in this line of research is that reliable firm-level information on product quality for a wide range of industries simply does not exist. In this paper, I develop and implement a methodology for obtaining plant-level estimates of product quality from revenue and physical output data. I use the estimates to decompose cross-plant variation in price and export status into a quality and an efficiency margin. The results suggests that the distinction between quality and efficiency matters in explaining the observed price and export patterns.

Because they do not have access to direct measures of product quality, researchers often resort to proxies such as unit values to make inferences about the role of product quality in determining export patterns. ${ }^{2}$ Firms that charge high prices are assumed to produce higher quality variety. However, using price variation to identify the impact of quality is misleading because many factors other than quality affect prices. For instance, holding quality fixed, more efficient firms may find it optimal to charge relatively low prices for their products. Hence, prices are at best imprecise measures of quality. It is therefore important to develop more accurate proxies for quality in order to better understand and quantify the impact of changes in product quality on price and export status.

In this paper, I define quality broadly as any product characteristic, tangible or intangible, that impacts consumers' willingness to pay. Because consumers decide how much to purchase of each good by comparing quality-adjusted prices, two firms that charge the same price but have different market shares must sell varieties of different quality. In particular, firms that sell large quantities of physical output conditional on price are classified as high quality producers. I use this insight to obtain estimates for quality using plant-level information on revenue and price. Essentially, I measure quality using demand residuals derived from estimated demand functions. While using demand residuals to infer quality

\footnotetext{
${ }^{1}$ Hallak and Sivadasan (2009) and Kugler and Verhoogen (2010) find that exporters charge higher prices then non-exporting firms within narrowly defined product categories. Manova and Zhang (2009) show that exporting firms that charge higher prices earn greater revenue in each markets and export to more markets. Finally, Baldwin and Harrigan (2010) report that the average unit value of exported goods is positively related to foreign market distance.

${ }^{2}$ See for instance the studies of Baldwin and Harrigan (2010), Hallak and Sivadasan (2009), Johnson (2010), Kugler and Verhoogen (2010), and Manova and Zhang (2009).
} 
is not new, I am, to the best of my knowledge, the first to obtain plant-level measures of product quality. ${ }^{3}$ This allows me to evaluate the relationship between product quality, price and export status at the producer level.

To organize the empirical analysis, I extend the Melitz (2003) model to include product quality differentiation amongst heterogeneous firms. As in the benchmark model, firms differ in their ability to produce varieties, so that high efficiency firms face lower marginal costs of production at any given quality level. ${ }^{4}$ In addition, I assume that product quality increases demand conditional on price and increases cost conditional on efficiency. In other words, product quality depends on the characteristics of the production technology and consumers see varieties produced with expensive technologies as higher quality. Therefore, firms that incur relatively high production costs obtain favorable demand shifts and can sell larger amounts of units at a given price.

The model predicts that prices are increasing in quality and decreasing in efficiency. This supports the argument that prices are imperfect measures of product quality. The model also shows that changes in quality and efficiency have similar effects on selection into exporting. Firms that can generate more revenue, whether because of quality or efficiency, self-select into the export market. Hence, while the quality extended model separately identifies product quality and technical efficiency, this distinction does not matter for explaining firm selection into exporting.

I confront the main predictions of the model with the data. First, I derive measures of product quality from estimated demand curves. The results suggest there is substantial variation in quality across plants and that the extent of quality dispersion varies across industry. Second, I use the quality estimates along with a measure of physical total factor productivity to disentangle the separate impacts of quality and technical efficiency on price and export status. The empirical results show that prices are increasing in quality and decreasing in efficiency as predicted by the model. Further, I find that exporters in my sample charge prices on average 5 percent higher compared to non-exporters. This correctly suggests that exporters produce higher quality varieties on average. However, consistent with the model, price variation underestimates the exporter quality premium. Using my

\footnotetext{
${ }^{3}$ Hummels and Klenow (2005), Hallak and Schott (2010), and Khandelwal (2010) use similar estimation procedures on bilateral trade flows to obtain country-level measures of product quality.

${ }^{4}$ Technical efficiency refers to the firm's cost advantage. As will be made clear later, in this paper, firm productivity is a mix of product quality and technical efficiency.
} 
measure of quality, I find that the quality of varieties sold by exporters is in fact more than 60 percent higher on average compared to varieties sold by non-exporters.

Finally, I look at the impact of changes in quality and efficiency on export status. The empirical results reveal that the probability of exporting is increasing in quality but that technical efficiency is not a good predictor of plant export status. This suggests that firms select into the export market because they are better able to generate demand for their product, not because they can produce at lower costs. At first, this result seems at odds with the empirical firm heterogeneity literature beginning with Bernard and Jensen (1995), which argues that more productive firms self-select into the export market. However, it is important to emphasize that previous empirical studies used revenue-based measures of productivity which confound the separate effects of technical efficiency and product quality on producer revenue and export status. In this paper, I decompose productivity into a quality and technical efficiency margin and find that exporters produce higher quality products but are not more efficient than non-exporters. Importantly, this does not change the fundamental result that exporters are more profitable - it simply provides a more detailed view.

The finding that changes in quality and efficiency have different impacts on export status forces us to rethink the assumptions of the quality model. In the benchmark model with ad valorem trade costs and constant markup changes in quality and efficiency have similar impact on export revenue and, as a result, selection into exporting. The final major contribution of this paper is to show that including per unit transport costs breaks the equivalence between quality and efficiency. ${ }^{5}$ This happens because per unit transport costs lead to a greater percentage change in prices for low quality varieties. Therefore, an increase in product quality that leads to the same increase in domestic revenue as a given change in efficiency is more likely to lead to entry into the foreign market. This result is related to the Alchian and Allen (1964) conjecture often described as "shipping the good apples out".

This paper complements a growing body of research in international trade that seeks to understand the role of product quality in explaining trade flows. For instance, Schott (2004), and Johnson (2010) use export prices to estimate the role of quality in explaining aggregate trade patterns while Baldwin and Harrigan (2010) and Manova and Zhang (2009)

\footnotetext{
${ }^{5}$ Hallak and Sivadasan (2009) suggests an alternative explanation. They argue that firms must satisfy the quality requirements of the foreign market in order to export. This seems plausible for firms in developing countries, however, it is less likely to be relevant in the case of US firms.
} 
look at firm-level variation in prices to study changes in quality across export destination. Because these papers use unit value as a proxy for quality, they cannot separately identify the impact of quality and efficiency on price and export status as is done in this paper.

My analysis is also closely related to the work of Hummels and Skiba (2004). They confirm the Alchian-Allen conjecture using extensive aggregate bilateral trade data and provide strong evidence against the widely used iceberg trade cost assumption. In this paper, I provide additional support for the per unit cost formulation using producer level information. In particular, I show that with per unit trade costs firm size is not a perfect predictor of export status.

Finally, in ongoing work, Foster et al. (2008b) suggest a dynamic explanation for the demand residuals that emphasis the role of learning. The authors argue that it takes time for consumers to learn about new products, so that older vintage varieties have an advantage over newly introduced ones. The two studies are complementary since my work emphasizes the contemporaneous relationship between quality, price and export status but is silent on the intertemporal accumulation of brand capital.

The remainder of the paper is structured as follows. In the next section, I develop a model of international trade that includes heterogeneity in quality and efficiency. I use the model to show how changes in product quality and technical efficiency interact to shape price and export patterns. In section 3, I describe the data set, define the main variables, and present summary statistics. In section 4 , I confront the model with the data. I begin by estimating price elasticities of demand from which I construct plant-level measures of product quality. I then use these estimates to explore the plant-level relationship between quality, price, and export status. In section 5, I extend the model to include per unit transportation costs and show how this helps reconcile the theory with the evidence. In section 6 , I describe robustness checks of the empirical results. In section 7, I present some conclusions and ideas for future research.

\section{Theoretical FrameWork}

In this section, I describe a straightforward extension of the Melitz (2003) framework that includes two dimensions of heterogeneity: product quality and technical efficiency. My framework is similar to the those of Johnson (2010) and Kugler and Verhoogen (2010). However, conversely to these other works, I do not model the quality decision. Instead, similar to Hallak and Sivadasan (2009), I assume that quality is a random draw like ef- 
ficiency. This implies that two firms with the same revenue can differ in terms of quality and efficiency. For instance, one can be a low quality high efficiency firm while the other is a high quality low efficiency. As a result, firm size and price are not perfect indicators of product quality.

\subsection{Preferences}

Consider an economy composed of a measure $L$ of infinitely lived consumers each endowed with one unit of labor per period. Consumers have no taste for leisure and inelastically supply their labor to the market at the prevailing wage rate. Consumers derive utility from the consumption of a continuum of differentiated varieties. The aggregate preferences are given by the following utility function:

$$
U=\left\{\int_{x \in X}[\omega(x) q(x)]^{\rho} d x\right\}^{1 / \rho}, \quad \rho \in(0,1),
$$

where $\omega(x) \geq 1$ is the quality and $q(x)$ the quantity consumed of variety $x$, while $X$ is the measure of varieties available for consumption. Product quality is a demand shifter that captures every product characteristics that increase demand conditional on price.

The consumption of each variety is chosen to minimize the cost of acquiring the aggregate consumption bundle $Q \equiv U$, so that the optimal aggregate expenditure on variety $x$ is:

$$
q(x)=R P^{\varepsilon-1}\left[\frac{p(x)}{\omega(x)}\right]^{-\varepsilon} \quad \text { with } \quad \varepsilon=\frac{1}{1-\rho},
$$

where $R$ is the total expenditure in the industry, $P$ is the ideal price index given by

$P=\left[\int_{x \in X}[p(x) / \omega(x)]^{1-\varepsilon} d x\right]^{\frac{1}{1-\varepsilon}}$, and $p(x)$ is the price of variety $x$. The preferences described in (1) are a version of the Dixit and Stiglitz (1977) aggregator extended to allow for substitution between quantity and product characteristics. This specification implies that the price elasticity of demand is the same for all varieties, independent of their characteristics, and is given by $\varepsilon$.

\subsection{Production}

Production uses only one input, labor. Total production costs depend on the quantity produced, the quality of the output and the firm's technical efficiency, denoted $\theta \in[1, \infty)$. I normalize the common wage rate to one without loss of generality and assume that the 
total cost function takes the specific form:

$$
L(x)=\frac{\omega(x)^{\eta}}{\theta(x)} q(x), \quad \text { with } \quad \eta \in(0,1)
$$

The total cost function implies that the variable cost is increasing in quality and decreasing in efficiency. The constant $\eta$ governs the quality elasticity of production costs. When it is large, a change in quality will lead to a greater increase production costs.

\subsection{International Trade}

I assume that the world is composed of two identical countries. ${ }^{6}$ As discussed in Roberts and Tybout (1997), plants must build and maintain relations with foreign distributors in order to sell their products in foreign markets. In addition, plants generally face tariffs and pay freight costs to send their products to foreign markets. These trade impediments take the form of a fixed export cost, denoted $f_{x}$, that must be paid once by firms to enter the foreign market and iceberg costs, $\tau>1$. If $\tau$ units are shipped to the foreign country, only one unit arrives. These costs are assumed to be common to all firms and constant with respect to quality.

\subsection{Profit Maximization}

All potential entrants face a common production start up costs, $f_{e}$. The value of the investment opportunity is learned only once the fixed entry cost is sunk and the firm learns its quality and efficiency - a random draw from a common joint distribution with cumulative density function $G(\omega, \theta)$. After learning its quality and efficiency, the firm simultaneously chooses the domestic and export price for its product and whether or not to enter the foreign market. The firm's profit maximization problem is a function of quality and efficiency and can be written as follows:

$$
\max _{p, p_{x}, I_{x}} \pi(\omega, \theta)=\left(p-\frac{\omega^{\eta}}{\theta}\right) q(p, \omega)+I_{x}\left[\left(p_{x}-\tau \frac{\omega^{\eta}}{\theta}\right) q\left(p_{x}, \omega\right)-f_{x}\right]
$$

\footnotetext{
${ }^{6}$ When countries are identical, they share the same aggregate variables, which greatly simplify the analysis. However, the main results do not depend on this assumption. Extending the model to include more than two countries is straightforward but keeping an eye on the empirical analysis provides no additional insights.
} 
where $p$ and $p_{x}$ represent the price of a domestic variety sold in the domestic and foreign markets respectively, $q(p, \omega)$ is the optimal demand defined in (2). The first term represents profits from domestic sales while the second term represents profit from exporting.

Profit maximization implies that firms will set marginal cost equal to marginal revenue. This leads to the following pricing rules:

$$
p(\omega, \theta)=\frac{\omega^{\eta}}{\rho \theta} \quad \text { and } \quad p_{x}(\omega, \theta)=\frac{\tau \omega^{\eta}}{\rho \theta} .
$$

These equations show that optimal prices are increasing in quality and decreasing in efficiency. Given the structure of preferences firms charge a constant markup, $1 / \rho$, above their production costs and shift the increase in marginal production costs associated with exporting $(\tau)$ to foreign consumers.

Given the assumptions on technologies and preferences, firms always make positive profits in their domestic market. However, firms will enter the foreign market only if the extra profits from exporting is greater than the fixed cost of exporting. Since profits depend on both quality and efficiency, the zero-profit efficiency threshold varies across quality and is given by:

$$
\theta_{x}(\omega)=\frac{\tau}{\rho P}\left(\frac{\varepsilon f_{x}}{R}\right)^{\frac{1}{\varepsilon-1}} \omega^{\eta-1} .
$$

Firms with quality $\omega$ will make non-negative profits in the foreign market only if their efficiency is above $\theta_{x}(\omega)$; in that case they export $\left(I_{x}=1\right)$ otherwise they don't $\left(I_{x}=0\right)$. To ensure that an increase in quality lowers the efficiency threshold, I assume that eta $\in(0,1)$. Intuitively, the conditional efficiency threshold is increasing in trade costs and decreasing in market size.

\subsection{EqUiLibrium}

Each period, incumbents face a probability $\delta \in(0,1)$ of being hit by exogenous shocks that will force them to exit the industry. Therefore, the expected value of staying in the market is equal to the stream of future profits discounted by the probability of exit: $V_{e}(\omega, \theta)=$ $\sum_{t=0}^{\infty}(1-\delta)^{t}\left[\pi_{d}(\omega, \theta)+I_{x}(\omega, \theta) \pi_{x}(\omega, \theta)\right]$. I assume that the characteristics of the joint distribution of quality and efficiency is common knowledge, so that the ex-ante expected value of entry is the same for all potential entrant and equal to the average firm value. There exists an unbounded set of potential entrants in the industry. Firms will attempt 
entry in the industry as long as the expected value from entry is greater then the sunk entry cost. In that case, the free entry condition is given by:

$$
\bar{\pi}=\delta f_{e}, \quad \text { with } \quad \bar{\pi}=\int_{\omega} \int_{\theta}\left[\pi_{d}(\omega, \theta)+I_{x}(\omega, \theta) \pi_{x}(\omega, \theta)\right] d G(\omega, \theta) .
$$

Finally, in a stationary equilibrium, aggregate variables must remain constant over time. This requires a mass of new entrants in each period, such that the mass of successful entrants exactly replaces the mass of incumbents forced to exit. This completes the characterization of the unique equilibrium.

\subsection{Analysis of Equilibrium}

An interesting property of the model is that it is isomorphic to a model in which there is a single dimension of heterogeneity - this is also true of models developed by Hallak and Sivadasan (2009), Johnson (2010) and Kugler and Verhoogen (2010). This can be shown by redefining quality and efficiency in terms of quality-adjusted units. Let $\hat{q}=\omega q$ denote the quality-adjusted physical output and $\hat{p}=p / \omega$ the quality-adjusted price. Then, from (2), the optimal demand for a variety depends only on its quality-adjust price and can be expressed has:

$$
q=R P^{\varepsilon-1} \hat{p}^{-\varepsilon}
$$

To obtain the production function in terms of quality-adjusted units, I define firm productivity as $\varphi(\omega, \theta)=\theta \omega^{1-\eta}$. This measure captures both the efficiency and the quality of the firm. I can then express total productions costs as:

$$
L=\frac{1}{\varphi} \hat{q}
$$

and rewrite the selection equation (6) as follows:

$$
\varphi_{x}=\frac{\tau}{\rho P}\left(\frac{\varepsilon f_{x}}{R}\right)^{\frac{1}{\varepsilon-1}} .
$$

The system of equations (8)-(10) is identical to the benchmark Melitz (2003) model - up to the fixed production costs.

Equation (10) clearly shows that variations in quality and efficiency that lead to equivalent changes in productivity and, as a result revenue, will have the same impact of selection. 
Therefore, while it helps to match price moments, decomposing productivity into a quality and an efficiency margin does not help explain export patterns. According to the model, two firms that generate the same revenue will have the same export status independent of their quality and efficiency. Of course this does not need to be the case in the data. The main objective of the empirical analysis is test this prediction.

\section{Data and Measurement}

The data set is derived from the Census of Manufactures (CM), a component of the U.S. Census Bureau's Economic Census. The CM is conducted every five years and covers the universe of manufacturing plants with one or more paid employees. Large- and medium-size firms, plus all firms known to operate more than one establishment, are sent questionnaires to be completed and returned to the Census Bureau by mail. ${ }^{7}$ Firms that receive this questionnaire are required by law (Title 13, United States Code) to respond. The same law ensures the report is confidential and can only be used by Census Bureau employees for statistical purposes.

The CM contains plant-level data on payroll, employment, book values of equipment and structures, cost of materials and energy, and plant-by-product data on the value of shipments. Starting in 1987, the CM also contains information on the value of export. In addition, for a subset of products, the CM collects plant-by-product information on shipments in physical units, which allows me to separate the value of shipments at the plant level into price and quantity. Only about 28 percent of plant-product-year observations in the CM have information on physical quantities. The information is not available when product data is being reported for the same period in surveys conducted by other Federal Government agencies. The selection occurs at the product level, so that when physical output is recorded in the $\mathrm{CM}$ it is available for all plants in that product class.

\subsection{SAMPLE}

The unit of observation is a plant-product-year combination. For the empirical analysis, products are defined as five-digit standard industrial classification (SIC) product classes. ${ }^{8}$

\footnotetext{
${ }^{7}$ For very small firms, which represent a small fraction of each industry's output, the reported data come from existing administrative records of other Federal agencies. Since product level information is not available for those plants, I remove them from the sample.

${ }^{8}$ Compared to four-digit industries, five-digit product classes removes a lot of horizontal differentiation from the analysis. For example, the four-digit SIC industry 2051, "Bread, Cake and Related Products"
} 
Because the CM does not collect information on factor inputs separately by product but rather at the plant level, the sample includes only the primary product of specialized plants. This reduces measurement problems in computing productivity measures. I consider a multi-product plant to be specialized if its primary product accounts for at least 50 percent of its total nominal value of shipments. In the CM, about 55 percent of plants are specialized. These plants account on average for about 70 percent of aggregate revenue in a given product class. About 20 percent of specialized plants export, compared to 25 percent for non-specialized plants. Finally, plants included in the sample receive on average 90 percent of their revenue from their primary product.

To ensure there is enough variation to estimate aggregate and plant fixed effects, I limit the sample to product classes with at least 10 observations in each year and at least 50 observations overall. Further, since plants that appear only once are dropped in fixedeffect estimation, the sample includes only products where more than half of the plant-year observations are related to plants that appear at least twice in the sample. Together, these rules lead to a sample of 52,263 observations distributed across 143 five-digit SIC product classes and three years, 1987, 1992 and $1997 .{ }^{9}$ The sample contains on average about half of a given product's plant-by-year observations, which together account for about 60 percent of the product's total shipment value. A list of five-digit SIC codes and descriptions for all products in the sample can be found in the appendix.

\subsection{Measurement}

The CM records domestic and foreign sales separately but contains only information on total physical output. This implies that I cannot compute domestic and foreign unit values

contains six five-digit products which are related in end use but differ in terms of material inputs and production technologies: Bread (20511); Rolls (20512); Sweet Yeast Goods (20513); Soft Cakes (20514); Pies (20515); Pastries (20518). Revisions to the SIC code system make it difficult to keep track of products over time while ensuring that the product's definition remains the same. Over the period 1987 to 1997 , the CM contains 1,931 distinct five-digit product-classes. I remove the five-digit codes that do not appear in all three censuses from the sample. These observations represent about 4 percent of plant-product-year observations and 8 percent of the total value of shipments in the CM. Finally, because variation in units of measurement prevents an accurate comparison of physical output and unit value, I drop product classes with heterogeneous units of measurement for quantity.

${ }^{9}$ I remove balancing codes, receipt for contract work, resale, and miscellaneous receipts from the sample because they are unrelated to production. In addition, I drop observations with missing information so that the sample remains the same in every estimation. In order to limit large reporting errors, I drop observations with an output price above 10 times or lower than one tenth of the product class's median price. These price outliers represent less than 2.5 percent of observations for which I can compute price. 
separately. According to the model, however, these are the same. Combining the optimal demand (2) and the pricing rules (5) shows that I can estimate (f.o.b.) prices using average unit values, defined as the ratio of the nominal product shipment value to physical quantity produced. I

I define physical total factor productivity $(Q T F P)$ as physical output per worker:

$$
Q T F P=\frac{q}{L}=\frac{1}{c}=\frac{\theta}{\omega^{\eta}} .
$$

This measure depends on product quality and firm efficiency. Holding efficiency fixed, QTFP is decreasing in product quality. This implies that, in the presence of quality differentiation, physical TFP is a biased measure of the producer's "true" technical efficiency level, $\theta$. This is not a problem for the current purpose as long as I control for quality in the regression. What is important, however, is that QTFP depends only on production costs and is not affected by demand-side effects that would influence prices. Traditional revenue total factor productivity $(R T F P)$ is defined as revenue per worker. In my model, it is equal to markups. In the data, markups can vary across firms in response to random demand shocks unrelated to efficiency. This makes RTFP an invalid instrument for price in a demand regression. ${ }^{10}$

I compute $Q T F P$ using the typical index form: $\ln T F P=\ln q-\psi_{K} \ln K-\psi_{L} \ln L-$ $\psi_{E} \ln E-\psi_{M} \ln M$, where $q, K, L, E$ and $M$ represent establishment-level output quantities, capital stocks, labor hours, and energy and materials inputs, and where $\psi_{j}$ for $j \in\{K, L, E, M\}$ are the factor elasticities for the corresponding inputs. ${ }^{11}$ For simplicity I assume that the input elasticities, $\psi$, are constant across quality and I estimate them using five-digit SIC average cost shares over the sample. ${ }^{12}$

\footnotetext{
${ }^{10}$ In my sample the correlation between price and $R T F P$ is positive, even after controlling for quality. This suggests that $R T F P$ is capturing random demand shock unrelated to product quality.

${ }^{11}$ I compute labor, materials, and energy cost shares from reported expenditures in the CM. The real capital stock is the sum of the plants' reported book values for their structures and equipment stocks deflated to 1987 levels using sector-specific deflators from the Bureau of Economic Analysis. Labor inputs are measured as plants' reported production-worker hours multiplied by the ratio of total payroll to production workers' payroll. I obtain the real cost of labor by multiplying the hours worked by the real wage. Real materials and energy inputs are plants' reported expenditures on each, deflated using the corresponding four-digit SIC input price indices from the NBER-CES Manufacturing Industry Database. For multi-product plants, I scale down all inputs using the primary product's share of the plant's nominal shipments. I construct the cost of capital by multiplying the real capital stock by the capital rental rate for the plant's respective two-digit industry. These rental rates are taken from unpublished data constructed and used by the Bureau of Labor Statistics in computing their Multi-factor Productivity series.

${ }^{12}$ This formulation implicitly assumes constant returns to scale. In general, each of the input elasticities
} 
Finally, since the CM does not collect information on export separately by product but rather at the plant level, I classify plants as exporter if they reports positive sales to foreign markets. Of course, this is an imperfect measure. However, my sample contains only specialized plants which derive on average 80 percent of their sales from a single product. It seems reasonable to assume that specialized exporting plants will sell their primary product in foreign markets.

\subsection{Sample Characteristics}

Table 1 shows summary statistics for the main variables. I remove product-year means from the variables before computing the statistics, so the results are not driven by product heterogeneity or aggregate shocks - I do the same for all regressions.

To give an idea of the variation in the data, I compute the standard deviations of plant $\log$ quantity, price, and physical total factor productivity $(Q T F P)$ for each product-year. The top panel of Table 1 presents the mean and standard deviation for each measure. The most important message is that there is substantial variation in plant characteristics within each product class and heterogeneity across product classes in the extent of the cross-plant variation. The table also shows the average share of plant-by-year observations classified as exporters. On average about 27 percent of plant-by-year observations are classified as exporters, which is about the same as in the whole CM. The share of exporters varies substantially across product classes.

The bottom panel of the table shows correlation between the main variables. The first point to note is that total physical output is decreasing in price and increasing in efficiency. A finding consistent with the model. Second, the negative correlation between efficiency and price is in line with the prediction that more efficient firms charge lower prices. Recall, however, that in the presence of quality differentiation this measure captures both the impact of changes in efficiency and quality. Therefore it understates the actual negative im-

$\psi_{j}$ should be multiplied by the scale elasticity. Baily, Hulten and Campbell (1992) and Olley and Pakes (1996) provide empirical support for the constant returns to scale assumption. Further, I find that the main results are robust to small deviations from unitary scale elasticities. Of course this is not the only method that can be used to estimate factor elasticities. Olley and Pakes (1996) and Levinsohn and Petrin (2003) suggests using either an instrumental variables procedure or proxy methods. These are not really appropriate in the current context. First, the sample is not an annual panel data. Second, the one-to-one mapping required between plant-level productivity breaks down if other unobservable plant-level factors besides productivity, such as the idiosyncratic demand shocks, drive changes in the observable proxy. Importantly, Van Biesebroeck (2004) finds high TFP correlations across various measurement alternatives. This suggests that alternative measures would not lead to first-order changes in the results. 
Table 1: SAmple Characteristics

\begin{tabular}{|c|c|c|c|c|}
\hline & \multicolumn{3}{|c|}{ Standard Deviation Across Plants of Log } & \multirow{2}{*}{$\begin{array}{l}\text { Share of } \\
\text { Exporters }\end{array}$} \\
\hline & Quantity & Price & QTFP & \\
\hline Mean & 1.39 & 0.52 & 0.60 & 0.27 \\
\hline \multirow[t]{3}{*}{ Standard Deviation } & 0.31 & 0.22 & 0.22 & 0.18 \\
\hline & \multicolumn{4}{|c|}{ Plants Level Correlation Between Log } \\
\hline & Quantity & Price & QTFP & Export Status \\
\hline Quantity & 1.00 & & & \\
\hline Price & -0.37 & 1.00 & & \\
\hline QTFP & 0.49 & -0.81 & 1.00 & \\
\hline Export Status & 0.20 & 0.04 & 0.01 & 1.00 \\
\hline
\end{tabular}

Notes: The top panel of the table shows the mean and the standard deviation of the within-product-year standard deviation across plants of quantity, price, and TFP. All variables are in logs and corresponding product-year means are removed from the variables before computing the statistics. The table also shows the mean and standard deviation across product classes of the fraction of exporters in each product-year categories. The bottom panel presents correlations between the variables. There are 143 different product classes. However, since three products appear in only two of the three sample years, the sample size is 423 .

pact of changes in efficiency on prices. Finally, exporters sell more units and charge slightly higher prices on average compared to non-exporters. The correlation between export status and efficiency is almost zero however.

\section{Empirical Analysis}

In this section, I use the theoretical model to evaluate the plant-level relationship between quality, efficiency, price, and export status. I begin by estimating demand equations separately for each market using price and quantity information. Then, I derive plant-level estimates for product quality from the estimated price elasticity of demand. Finally, I confront the model's main predictions with the data by estimating the impact of changes in quality and efficiency on unit price and the probability of exporting.

\subsection{Price Elasticity of Demand}

Equation (2) above shows how consumers combine product price and quality to determine their optimal demand for a particular variety. This equation suggests that product quality can be estimated from unobserved plant-level effects in regressions of quantity on price and 
additional controls. Adding a multiplicative error term to the optimal demand and taking logs yields:

$$
\begin{aligned}
\ln q_{i t} & =\ln R_{t}+(\varepsilon-1) \ln P_{t}+I_{i t}^{x} \ln \left(1+\tau_{t}^{-\varepsilon}\right)-\varepsilon \ln p_{i t}+\varepsilon \ln \omega_{i}+e_{i t} \\
& =\beta_{t}+\beta_{i t}^{x}-\varepsilon \ln p_{i t}+\nu_{i}+e_{i t},
\end{aligned}
$$

where $i$ and $t$ index plants and year respectively. The first term is a time-varying effect common to all plants that captures variation in market characteristics over time. The second term controls for the increase in demand associated with entering the foreign market but unrelated to variations in price and quality. ${ }^{13}$ If I do not control for export status in the demand regression I would overestimate the quality of exporting firms. The fourth term, $\nu_{i}$, is a plant unobserved effect equal to the product of the price elasticity of demand and the time-invariant product quality. If I don't control for quality in the demand equation, the estimates for the price elasticity of demand will be biased toward zero because of the positive correlation between price and quality. Therefore, I control for quality using plant-level fixed effects. Finally, the error term $e_{i t}$ represent idiosyncratic demand shocks.

If firms can respond to positive random demand shocks by raising their prices, estimating (12) by OLS produces biased estimates of the price elasticity of demand and, as a result, of the plant's output quality. Instead, I use the plant's physical total factor productivity $(Q T F P)$ as an instrument for price. ${ }^{14}$ The two-stage least squares (2SLS) fixed effect procedure using $Q T F P$ as an instrument for price produces consistent estimates under two identifying assumptions. First, the instrument must be relevant. As explained above, QTFP reflects idiosyncratic technologies (i.e. production costs), so they should have explanatory power over prices. Further, as seen in Table 1, there is a strong negative correlation between price and QTFP. Second, the instrument must be exogenous. This requires that the plant-year residual is uncorrelated with included regressors in every period. This condition is stronger than assuming zero contemporaneous correlation. However, it still allows for arbitrary correlation between the plant unobserved effect and the other

\footnotetext{
${ }^{13}$ The data does not contain separate information on quantity sold in the domestic and foreign market. I only observe total physical output. However, the theoretical model shows that f.o.b prices are the same in both markets and that the share of revenue from export is the same for all exporters.

${ }^{14} \mathrm{~A}$ potential problem with using $Q T F P$ as an instrument is measurement error. Since I estimate prices by dividing revenue by physical output, measurement error in quantities will overstate the negative correlation between price and QTFP. In that case measurement error provides biased estimates of the fitted prices used in the second stage and, as a result, biased price elasticities and quality measures. To solve this issue I use lag values of productivity. The main results do not seem to be driven by measurement error.
} 
explanatory variables. Therefore, the estimated price elasticity of demand are consistent despite the positive correlation between quality and price.

I estimate the demand equation (12) separately for each of the 143 five-digit products using both OLS and a 2SLS instrumenting price with $Q T F P$. The results are summarized in Table 2. The IV estimates of demand elasticity have a mean of 1.18 , which is about 30 percent lower on average than the corresponding OLS elasticity. ${ }^{15}$ These results suggests that there is a positive correlation between exogenous random demand shocks and prices, which biases OLS estimates of demand elasticities toward zero. The standard deviation for the estimated elasticities are generally small. About 95 percent of the IV and 91 percent of OLS elasticities are statistically significant at the 5 percent level. The mean within group $R^{2}$ is about 0.5 , which implies that changes in price and aggregate factors explain about half of the variation in quantity demanded once quality is controlled for. Further, the IV estimates of demand elasticities are relatively well behaved compared to the OLS estimates. All point estimates for the IV elasticities are negative and, for about 95 percent of them, I cannot reject the hypothesis that they are smaller than minus one, compared to 80 percent for the estimated OLS elasticities. Finally, the first stage $F$ statistics are larger than 10, the Staiger and Stock (1997) rule of thumb, for about 95 percent of product classes. This suggest that variation in $Q T F P$ has sufficient explanatory power over price. Overall, these results support the use of the 2SLS estimation procedure.

\subsection{Product Quality}

By definition, the plant unobserved effects $\left(\nu_{i}\right)$ capture time-invariant changes in physical output across plants uncorrelated with movements along the demand curve. In other words, they capture long-run shifts in the plant's demand curve. From the model, I can obtain estimates for product quality from the firm unobserved effects and the estimated price elasticity as follows: $\hat{\omega}_{i}=\exp \left(\hat{\nu}_{i} / \hat{\varepsilon}\right)$. I report some characteristics of this plant-level proxy for product quality at the bottom of Table 2. The results for the OLS and IV estimates are almost identical, so I concentrate on the IV results.

First, I test the null hypothesis that the plant unobserved effects $\left(\nu_{i}\right)$ are all equal to

\footnotetext{
${ }^{15}$ In the theoretical model, the markup over cost depends only on the price elasticity of demand. Precisely, the markup is equal to $1 / \rho=\varepsilon /(\varepsilon-1)$. In that case, the estimated elasticities imply very high markups. The average estimated elasticity of 1.18 translates into a markup of about 6.5 . While this result is somewhat disappointing, it does not undermine the whole procedure. What matters for the empirical analysis is within industry variation in quality, not the levels per se.
} 
Table 2: Price Elasticity of Demand and Quality

\begin{tabular}{lcc}
\hline \hline & OLS & IV \\
\cline { 2 - 3 } Mean Estimated Elasticity & -0.89 & -1.18 \\
Mean Standard Deviation & 0.15 & 0.21 \\
Mean within group $R^{2}$ & 0.48 & 0.46 \\
Mean First Stage $F$ & $\mathrm{n} / \mathrm{a}$ & 369 \\
Share of $\varepsilon<0$ & 0.99 & 1.00 \\
Share of $\varepsilon<-1$ & 0.80 & 0.94 \\
\hline Mean $F$-statistic $H_{0}: \nu_{i}=0$ & 16.2 & 15.1 \\
Standard Deviation of $\nu_{i}$ & 1.26 & 1.31 \\
Standard Deviation of $e_{i t}$ & 0.41 & 0.43 \\
Mean share of variance due to $\nu_{i}$ & 0.90 & 0.90 \\
\hline \hline
\end{tabular}

Notes: This table summarizes the results from estimating the demand equation, defined in (12), separately for each of the 143 five-digit product classes. I control product quality using plant unobserved effects $\left(\nu_{i}\right)$. I present results from OLS and 2SLS using physical TFP as an instrument for price. The average sample contains 365 observations.

0 for each product class. The average test statistics is greater than 15 and I reject the null at the 5 percent level in all product classes. Second, the average within-product standard deviation of the estimated plant fixed effect $\left(\nu_{i}\right)$ is 1.26 . Therefore, there is abundant and statistically significant cross-plant variation in the estimated long run demand shifts. There is also a lot of dispersion in the time varying demand shocks. However, most of the variation in quantity demanded unexplained by price, export status, and aggregate factors is due to the plant unobserved effects. As reported in the table, an average of 90 percent of the variance in the overall error term $\left(\nu_{i}+e_{i t}\right)$ is due to the plant's fixed effects $\left(\nu_{i}\right)$.

\subsection{Unit VAlue}

In this section, I use the estimates for product quality to decompose price variation into a quality and a productivity margin. From the pricing rule defined in (5), the log of the optimal price can be expressed as follows:

$$
\ln p_{i t}=\beta_{t}+\beta_{\omega} \ln \hat{\omega}_{i}+\beta_{\theta} \ln \hat{\theta}_{i t}+e_{i t}
$$

The first term on the right hand side of the equality, $\beta_{t}$, is constant common to all plants which captures the effect of markup on price. The second and third terms control for the impact of efficiency and quality on price and is measured using estimated $Q T F P_{i t}$ 
while quality is derived from the estimated demand shift and price elasticity of demand, $\omega_{i}=\exp \left(\nu_{i} / \varepsilon\right)$. Finally, the error term includes other exogenous factors affecting price. A central prediction of the theoretical model is that the quality elasticity of price is positive $\left(\beta_{\omega}>0\right)$, and that an increase in efficiency decreases price $\left(\beta_{\theta}<0\right)$.

For the estimation, I normalize all variables by removing product-year mean and dividing by product-year standard deviation. Therefore aggregate factors and product class heterogeneity do not drive any of the results. The normalization does not affect the qualitative properties of the results but makes their interpretation more intuitive since the coefficients represent the impact of a one standard deviation change in the independent variables. The results from estimating (13) are presented in Table 3. The benchmark results are presented in the first column. As predicted by the model, prices are increasing in quality and decreasing in productivity. According to the $R^{2}$ statistic, changes in quality and efficiency jointly explain about 60 percent of the within product-year variation in price in my sample. ${ }^{16}$

There are important caveats related to using price as a dependent variable. First, in the model the markup does not depends on demand or any producer characteristics. This is due to the specific form of the utility function. However, variation in markup is potentially an important source of variation in price. For instance, firms could choose to reduce their markup in order to attract larger market shares. In that case, the estimated coefficients on quality and efficiency are likely to be biased if I don't control for markup in the price regression. Second, because quality is a demand residual it could potentially capture other factors that increase demand but are unrelated to quality. For instance, as explained in Foster et al. (2008a), horizontal differentiation (e.g. firm specific history or location) can lead to variation in demand and higher prices. Third, since price and quality estimates are obtained from quantity information there could be correlated measurement error between the two.

To resolve these issues, I re-estimate equation (13) using unit production costs. ${ }^{17}$ From

\footnotetext{
${ }^{16}$ In the presence of generated regressors estimated in a "first stage", such as quality or $Q T F P$, inferences based on the usual OLS standard errors will be invalid since they ignore the sampling variation due to the estimation of these variables - see Wooldridge (2002). Instead, for the remainder of the analysis, I report bootstrap standard errors (Efron and Tibshirani (1986)). In the current context, the bootstrap is an appealing alternative to the use of asymptotic theory since it does not require a closed form solution for the variance-covariance matrix, which is difficult to obtain and evaluate. As it happens, the difference between the bootstrapped and the usual OLS estimated standard errors clustered by plant is small in the current analysis, and using clustered standard errors would not change the main results.

${ }^{17}$ I define total costs has the sum of production worker payroll, cost of material inputs and expenditure
} 
Table 3: The Determinants of Price

\begin{tabular}{lcccc}
\hline \hline Variables & Unit Value & Unit Cost & Homogeneous & Differentiated \\
\hline Log Quality & 0.232 & 0.167 & 0.060 & 0.351 \\
& $(0.047)$ & $(0.047)$ & $(0.009)$ & $(0.060)$ \\
Log Efficiency & -0.786 & -0.938 & -0.825 & -0.777 \\
& $(0.015)$ & $(0.012)$ & $(0.013)$ & $(0.015)$ \\
Sample Size & 52,263 & 52,263 & 21,439 & 30,824 \\
$R^{2}$ & 0.604 & 0.848 & 0.675 & 0.592 \\
SE of reg. & 0.627 & 0.388 & 0.568 & 0.637 \\
\hline \hline
\end{tabular}

Notes: This table shows the OLS results from regressing plant-level prices and, for the second column only, unit costs of production on the proxy for product quality and a measure of technical efficiency. All variables are in logs and are standardized by removing the corresponding product-year mean and dividing by the product-year standard deviation. The sample is the pooled sample of 52,263 plant-year observations, except for the last two columns where I divide the observations into two categories, homogeneous (goods traded on an organized exchange and reference priced) and differentiated, according to the Rauch (1999) classification. Bootstrap standard errors are in parenthesis.

the model, the only difference between unit costs and price is the markup. So the impact of quality and efficiency on unit costs should be exactly the same as that on price. Further, horizontal differentiation will affect prices through variation in markups but should not be related to production costs. Finally, units costs will not be correlated with measurement error in quality because they are constructed from input information instead of physical output. I report the results using production costs in the second column of Table 3. As was the case for prices, I find that unit production costs are increasing in quality and decreasing in efficiency. However, the impact of efficiency is statistically significantly larger when using per unit production costs than when using price. Finally, the $R^{2}$ is much higher when I use unit production costs, suggesting that markups are influenced by many factors, other than quality and price, that do not impact unit costs.

While pooled regressions are instructive and provide useful benchmark results, it is likely that the effects of changes in quality and efficiency on prices varies in response to changes in market and product characteristics. Therefore imposing the equality of the coefficients across products potentially masks important variation. I use the classification suggested by Rauch (1999) to separate product classes into two groups: homogeneous (includes reference price) and differentiated. ${ }^{18}$ I report the results in that last two columns

on energy. Per unit production costs are then computed by dividing total variable costs by total physical output.

${ }^{18} \mathrm{I}$ could separate products based on standard deviations of quality but it seems more compelling to use 
of Table 3. The results show that, as expected, changes in product quality have greater impact on prices in differentiated product classes. Meanwhile, the impact of efficiency on price is negative, statistically significant, and of similar magnitude in both categories of product classes.

The estimated correlations between price, quality and efficiency suggest that the estimated demand residuals are not random shocks and provide support to the quality interpretation. Plants with high estimated quality tend to charge higher prices and pay more per unit produced. Moreover, quality has a greater impact on prices in differentiated product classes.

\subsection{Exporter Price Premium}

Recent papers by Hallak and Sivadasan (2009) and Kugler and Verhoogen (2010) have found a positive association between unit value and export status. They regress firm prices on an export dummy controlling for size and find that exporters charge on average prices about $10 \%$ higher than non-exporters. A plausible explanation is that exporters produce varieties of higher quality than domestic plants. However, because firm size and export status are both correlated with quality and efficiency, the quality interpretation of the estimated coefficient on the export dummy is intricate. Instead, I can use the quality estimates to directly evaluate the correlation between price, quality, efficiency and export status.

From the pricing equation (5), the model predicts that the export status of the plant should have no effect on the optimal price once quality and efficiency are controlled for. To see if this prediction holds, I re-estimate the price regression (13) including a plant export status dummy:

$$
\ln p_{i t}=\beta_{t}+\beta_{t}^{x} I_{i}^{x} t+\beta_{\omega} \ln \hat{\omega}_{i}+\beta_{\varphi} \ln \hat{\theta}_{i t}+e_{i t}
$$

where $\beta_{i t}^{x}$ controls for the impact of export status, $\hat{\omega}_{i}$ is the estimated demand residual which serves as a proxy for log product quality, $\hat{\theta}_{i t}$ is the estimated plant efficiency, and $e_{i t}$ represents exogenous idiosyncratic shocks that affect prices.

I report the results from estimating (14) in Table 4. In the first column, I regress price on the export dummy alone. I find that exporters charge prices on average about a tenth

outside information. The sample contains about a dozen product classes not included in Rauch's classification. I classify those based on the product descriptions. Removing them from the sample does not affect the main results. 
Table 4: The Exporter Price Premium

\begin{tabular}{lccccc}
\hline \hline Variables & Premium & Unit Value & Unit Cost & Homogeneous & Differentiated \\
\hline Export Status & 0.099 & 0.017 & 0.004 & 0.032 & 0.002 \\
& $(0.018)$ & $(0.020)$ & $(0.019)$ & $(0.009)$ & $(0.029)$ \\
Log Quality & & 0.230 & 0.166 & 0.057 & 0.350 \\
& & $(0.044)$ & $(0.048)$ & $(0.011)$ & $(0.057)$ \\
Log Efficiency & & -0.786 & -0.938 & -0.825 & -0.777 \\
& & $(0.014)$ & $(0.011)$ & $(0.014)$ & $(0.014)$ \\
Sample Size & 52,263 & 52,263 & 52,263 & 21,439 & 30,824 \\
$R^{2}$ & 0.002 & 0.604 & 0.848 & 0.675 & 0.592 \\
SE of reg. & 0.995 & 0.627 & 0.388 & 0.568 & 0.637 \\
\hline \hline
\end{tabular}

Notes: This table shows the OLS results from regressing plant-level prices and, for the second column only, unit costs of production on the export indicator variable, the proxy for product quality and a measure of technical efficiency. All variables are in logs and are standardized by removing the corresponding productyear mean and dividing by the product-year standard deviation. The sample is the pooled sample of 52,263 plant-year observations, except for the last two columns where I divide the observations into two categories, homogeneous (goods traded on an organized exchange and reference priced) and differentiated, according to the Rauch (1999) classification. Bootstrap standard errors are in parenthesis.

of a standard deviation higher than domestic plants. In column (2), I estimate a richer specification that includes quality and efficiency. The export dummy is still positive but much smaller and no longer statistically significant. The estimated coefficient on quality and efficiency have the expected sign and are statistically significant. Consistent with the model's prediction, these results imply that plant export status does not explain price variation when controlling for changes in quality and efficiency.

In the second column of Table 4 I use unit production costs instead of price. As for price, export status does not explain variation in costs once quality and efficiency are controlled for. Finally, in the last two columns of Table 4, I estimate the price equation separately for product classes classified as homogeneous and those classified as heterogeneous. For differentiated products the results are the same as in the benchmark. Prices are increasing in quality and decreasing in efficiency and plant export status has no impact on prices. However, I find that for homogeneous goods, the export status is positive and statistically significant even after controlling for quality and efficiency. This may suggests that there are decreasing returns to scale in the production of homogeneous goods. If exporters are larger on average then entry in the foreign market will increase costs and, as a result, prices even after controlling for quality and efficiency. 
TABle 5: EXPORTERs vs. NON-EXPORTERs CharaCteristics

\begin{tabular}{lccccc}
\hline \hline Variables & Unit Value & Quality & QTFP & Productivity & $\mathrm{N}$ \\
\hline Non-exporters & -0.01 & -0.12 & -0.001 & -0.02 & 41,602 \\
& $(0.45)$ & $(1.09)$ & $(0.54)$ & $(0.64)$ & \\
Exporters & 0.04 & 0.46 & 0.005 & 0.07 & 10,661 \\
& $(0.57)$ & $(1.24)$ & $(0.62)$ & $(0.60)$ & \\
t-stat for equal mean & -7.99 & -43.47 & -1.01 & -12.67 & \\
\hline \hline
\end{tabular}

Notes: This table shows within group means and standard deviations (in parenthesis) across-plants of unit value, product quality, physical TFP and labor productivity for exporters and non-exporters. All variables are in logs and I remove corresponding product-year mean such that aggregate factors and product heterogeneity do not drive the results. The table also shows the Welch's $t$ statistics for equality of means across groups.

\subsection{Export Status}

There is a vast literature that documents systematic differences across plants that export and plants that produce only for the domestic market - See Bernard et al. (2007) for a review of that literature. I also find that exporters are different than non-exporters in my sample. They produce more output, generate more revenue and employ more workers. In addition, as reported in Table 5, I find that exporters charge higher prices and produce higher quality goods on average compared to non-exporters. In my sample, exporters charge prices $5 \%$ higher on average compared to non-exporters. However, price variation does not capture the full extent of quality variation because of the opposite impacts of productivity on price. Using my proxy for product quality, I estimate that the average quality of exporter's output is about 58 percent higher than that of non-exporter. This estimate, the first of its kind, shows that the exporter quality premium is one order of magnitude larger than the exporter price premium.

I report the Welch's $t$ tests for equality of means across groups at the bottom of the table. According to this statistics, the differences in price and quality are statistically significant. However, I find that domestic plants are just as technically efficient as exporters. ${ }^{19}$ This result seems at odds with the important firm heterogeneity literature. As a check, I also calculated the mean labor productivity, defined as revenue over total hours worked. In line with previous studies, I find that exporters have statistically higher labor productivity.

\footnotetext{
${ }^{19}$ It is important to note that, as explain in detail in the appendix, TFP measures are generally downward biased when quality is not directly control for. Further, this bias is more important for exporters. This can explain, at least in part, that there is only a very small difference in TFP across exporters and non-exporters.
} 
This implies that differences in productivity measures and not sample characteristics drive the results.

In the model, firms enter the export market only if the extra profit from exporting is positive. Using the pricing rule, it is possible to express the ratio of foreign variable profits to fixed export costs as:

$$
T=\frac{R(\rho P)^{\varepsilon-1}}{\varepsilon f_{x} \tau^{\varepsilon-1}} \omega^{\varepsilon-\eta(\varepsilon-1)} \theta^{\varepsilon-1} .
$$

The variable $\mathrm{T}$ is the product of two main components. The first depends exclusively on market characteristics and is common to all plants. The second is plant specific and depends on product quality and efficiency. I estimate the probability that plant $i$ exports at time $t$ conditional on the observed variables from the following Probit equation:

$$
\operatorname{prob}\left\{I_{i t}^{x}=1 \mid \text { Observed Variables }\right\}=\Phi\left(\beta_{t}+\beta_{\omega} \ln \hat{\omega}_{i}+\beta_{\varphi} \ln \hat{\theta}_{i t}\right)
$$

where $\Phi$ is the cumulative density function of the unit-normal distribution. As before, $I_{i t}^{x}$ is an export indicator variable equal to 1 when the plant exports, and 0 when it does not. I allow the constant $\beta_{t}$ to vary over time to account for possible changes in trade costs over time.

I present the results from estimating Probit equation (15) in Table 6. As predicted quality has a positive, and significant impact on the probability of exporting. However, while the coefficient on $Q T F P$ is positive, it is very small and not statistically significant. This result is not surprising given that, as reported in Table 5, non-exporters are on average just as technically efficient as exporters. However, as shown in the third column, I find that an increase in labor productivity increases the probability of export. This difference in results arise because the revenue-based measures of productivity confound demand- and supply-side effects on profitability and the decision to export. As can be seen from the last two columns, once quality is controlled for, I find that using productivity instead of QTFP yields similar results. According to the point estimates a one deviation increase in quality increases the probability of export by about 8 percent. Meanwhile, an increase in productivity as a negative, but small and arguably economically insignificant, impact on the probability of export. 
Table 6: The Determinants of Export Status

\begin{tabular}{lccccc}
\hline \hline Variables & $(1)$ & $(2)$ & $(3)$ & $(4)$ & $(5)$ \\
\hline Log Quality & 0.078 & & & 0.081 & 0.084 \\
& $(0.002)$ & & & $(0.002)$ & $(0.002)$ \\
Log TFP & & 0.001 & & -0.013 & \\
& & $(0.002)$ & & $(0.002)$ & -0.014 \\
Log Productivity & & & 0.022 & & $(0.002)$ \\
& 0.036 & 0.000 & 0.003 & 0.037 & 0.037 \\
Pseudo $R^{2}$ & $-25,481$ & $-26,438$ & $-26,365$ & $-25,454$ & $-25,456$ \\
Log Pseudo Likelihood & &
\end{tabular}

Notes: This table shows the results from Probit regressions. The dependent variable is a dummy variable equal to 1 if the plant reports positive exports in the period and 0 otherwise. The proxy for product quality is the estimates plant time-invariant demand shift divided by the estimated price elasticity of demand. There are two measures of productivity. TFP denotes physical TFP, while productivity refers to labor productivity, defined as revenue divided by hours worked. The measures of quality and productivity are in logs and are standardized by removing the corresponding product-year means and dividing by product-year standard deviation. The sample is the pooled sample of 52,263 plant-year observations. Bootstrap standard errors are in parenthesis.

\section{Per Unit Trade Costs}

The finding that productivity plays no role in determining the plant's export status runs against the model's prediction that revenue is a sufficient statistics for export status. In the model, the combination of ad valorem trade costs and constant markup implies that changes in quality and efficiency have similar impact on foreign revenue and, as a result, export status. In this section, I show that this is not the case in the presence of per unit transportation costs.

The structure of the firm's profit maximization problem remains essentially the same. The only difference is that firms now incur a constant transportation costs, $t$, for each unit they sell in the foreign market. The problem can be written as follows:

$$
\max _{p, p_{x}, I_{x}} \pi(\theta, \omega)=\left(p-\frac{\omega^{\eta}}{\theta}\right) q(p, \omega)+I_{x}\left[\left(p_{x}-t-\tau \frac{\omega^{\eta}}{\theta}\right) q\left(p_{x}, \omega\right)-f_{x}\right]
$$

where $p$ and $p_{x}$ represent the price of a domestic variety sold in the domestic and foreign markets respectively, $q(p, \omega)$ is the optimal demand defined in (2). Profit maximization 
leads to the following pricing rules:

$$
p(\theta, \omega)=\frac{\omega^{\eta}}{\rho \theta} \quad \text { and } \quad p_{x}(\theta, \omega)=\frac{1}{\rho}\left(t+\frac{\tau \omega^{\eta}}{\theta}\right) .
$$

The optimal price in the domestic market is the same as before. However, the foreign price now includes per unit transport costs. Of course, the crucial difference between ad valorem and per unit costs is that the impact of per unit costs on prices is independent of firm characteristics (quality and efficiency).

From (16), the ratio of export to domestic price depends on quality as follows:

$$
\frac{p_{x}(\theta, \omega)}{p(\theta, \omega)}=\tau+\frac{t \theta}{\omega^{\eta}}=\tau+t \frac{\varphi(\omega, \theta)}{\omega}
$$

where, as before, $\varphi(\omega, \theta)$ is the firm's productivity. As expected, the markup over domestic price is increasing in trade costs. Less obvious, however, is the fact that this markup is decreasing in quality and increasing in efficiency. This happens because an increase in quality raises domestic price thereby reducing the percentage increase in price associated with the per unit transport cost. Efficiency has the opposite impact. Further, holding productivity fixed, an increase in quality will reduce the markup over domestic price. Therefore, in the presence of per unit transport costs changes in quality and efficiency that leave productivity unchanged have different impact on export behavior.

Consider two exporting firms with the same productivity but different quality and efficiency: $\varphi\left(\omega_{1}, \theta_{1}\right)=\varphi\left(\omega_{2}, \theta_{2}\right)$. For concreteness, suppose that firm 1 produces a higher quality variety $\omega_{1}>\omega_{2}$. It is straightforward to show that the ratio of export revenues for these two firms is given by:

$$
\frac{r_{x}\left(\theta_{1}, \omega_{1}\right)}{r_{x}\left(\theta_{2}, \omega_{2}\right)}=\left(\frac{\omega_{1}}{\omega_{2}}\right)^{\varepsilon-1} .
$$

Therefore, conditional on productivity, high quality firms will be larger because they sell more in the foreign market. However, since domestic revenue depends only on productivity, these two firms will have the same domestic sales.

This result is illustrated in Figure 1. The graph illustrates all possible quality-efficiency pairs. Firms with the same productivity or, equivalently, the same domestic revenue lie on a straight line through point $(1,0)$. Consider first the benchmark model with only ad valorem trade costs. In that case, the decomposition of productivity in quality and efficiency does not matter for selection. As shown in equation (6), firms that are productive enough will 


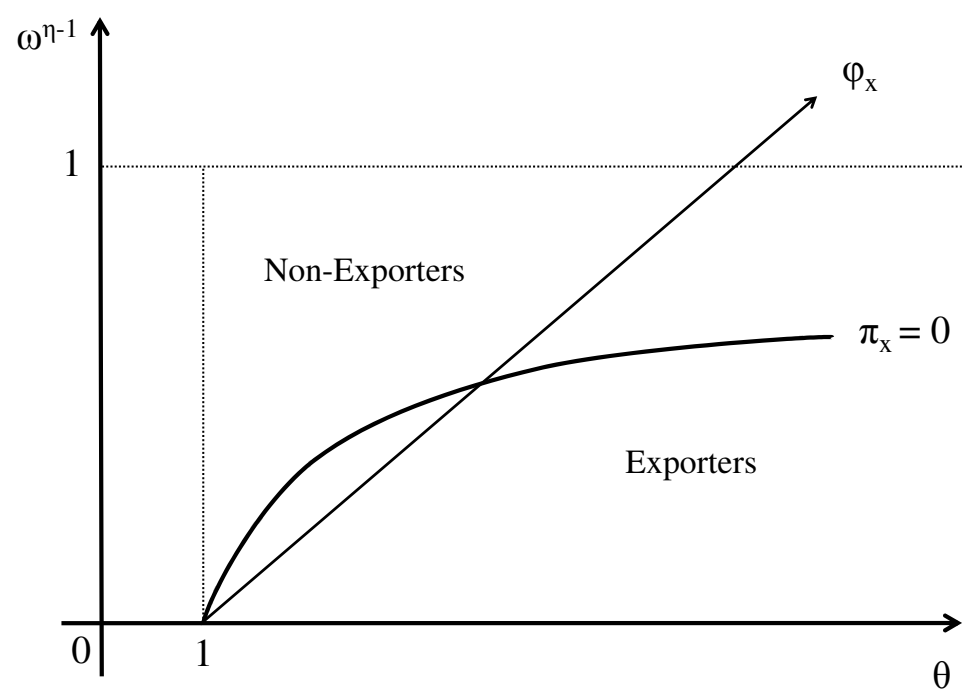

Figure 1: Quality, efficiency and export status

export. In terms of the graph, the productivity threshold is indicated by the diagonal $\varphi_{x}$. Firms with combinations of quality and efficiency that lie below that line will export - the graph is in inverse quality space because $\eta \in(0,1)$. When we add per unit costs, however, the threshold quality required for export profitability is no longer a linear function of efficiency. The zero export profit mapping from efficiency to quality is given by:

$$
\theta_{x}(\omega)=\frac{\tau}{\rho P}\left(\frac{\varepsilon f_{x}}{R}\right)^{\frac{1}{\varepsilon-1}}\left[1-\frac{t}{\rho P \omega}\left(\frac{\varepsilon f_{x}}{R}\right)^{\frac{1}{\varepsilon-1}}\right]^{-1} \omega^{\eta-1}
$$

In the graph this mapping is represented by the curve denoted $\pi_{x}=0$. This implies that conditional on productivity, only high quality firms will now export. For instance, consider firms with productivity level $\varphi_{x}$. Only those firms with quality that lies below the export profitability mapping will export. This implies that, in the presence of per unit trade costs, quality and efficiency do not have equivalent effects on export status. 
Table 7: Robustness Checks

\begin{tabular}{lcccc}
\hline \hline & Benchmark & Sample & Geography & Capacity \\
\hline Export Status & 0.017 & -0.001 & 0.029 & 0.022 \\
& $(0.021)$ & $(0.025)$ & $(0.001)$ & $(0.021)$ \\
Log Quality & 0.23 & 0.224 & 0.069 & 0.223 \\
& $(0.048)$ & $(0.056)$ & $(0.014)$ & $(0.047)$ \\
Log TFP & -0.786 & -0.825 & -0.761 & -0.786 \\
& $(0.015)$ & $(0.016)$ & $(0.024)$ & $(0.015)$ \\
Sample Size & 52,263 & 34,831 & 52,263 & 52,263 \\
$R^{2}$ & 0.604 & 0.622 & 0.581 & 0.601 \\
SE of reg. & 0.627 & 0.599 & 0.645 & 0.631 \\
\hline \hline
\end{tabular}

Notes: This table summarizes the results of exercises designed to test the robustness of the benchmark results to the maintained assumptions. The dependent variable is the plant log average unit value. The first column reproduces the benchmark results from the second column of Table 4. In the second column, I restrict the sample to observations for which I can separately identify the plant unobserved effect and residual term. In the third column, I control for regional factor and plant age. In the fourth column, I use a measure of productivity robust to cyclical changes in factor utilization. Bootstrap standard errors are in parenthesis. The sample is the pooled sample of 52,263 plant-year observations.

\section{Robustness}

In this section, I provide details on the robustness of the results to the maintained assumptions. First, in the model I associate quality with long run shifts in demand. Therefore, I estimate quality using plant-level fixed effect. This requires that plants appears at least twice in my sample. This is not always the case. As explained in the data section above, I restrict my sample to product classes for which more than half of the plant-year observations are related to plants that appear more than once. However, I include all the plants in the price, export price premium and export status regressions. For plants that appear only once, the estimated quality therefore contains both the long run demand shift and the idiosyncratic demand shock. Since the expected value of the random shocks is zero, the estimated quality is accurate on average. However, it is still important to evaluate the separate impact of each component. In the fourth column, I restrict the sample to plant-year observations for which I can partial out the impact of demand shocks $(u)$ and compute quality $(\omega)$. The results are similar to the benchmark. Price is increasing in quality and decreasing in productivity but the export status does not affect price.

Second, as explained in last section, the proxy for quality includes information on factors uncorrelated with productivity that also influence the demand for a particular variety. 
In the theory, firms compete face common aggregate conditions. However, in reality, many industries are segmented into multiple regional markets. Syverson (2004) shows that differences in regional demand and competition are important sources of price heterogeneity. Further, because it takes time for consumers to learn about new products, older vintage varieties may have an advantage over newly introduced ones. Foster et al. (2008b) find empirical support for this conjecture using U.S Census micro data on manufacturing plants. ${ }^{20}$ My theoretical model does not account for the accumulation of quality capital such as brand recognition or consumer habits, but rather concentrates on the contemporaneous relationship between production costs and demand. I re-estimate the demand equation (12) including regional indicators and plant age to partial out the fraction of demand explained by regional difference in demand and learning from the estimated plant unobserved effects. ${ }^{21}$ I estimate the impact of quality on price using this new proxy and present the results in the last column of Table 7 . The main results of interest are not affected by this change: prices are increasing in quality and decreasing in productivity, and the export status is not significant.

Finally, Burnside et al. (1996) and Basu et al. (2006) present empirical evidence that factor utilization is procyclal. If this is the case, the capital stock is not an accurate measure of capital utilization and which leads to biased estimates of efficiency. The authors suggest using energy usage to proxy for capital utilization. Therefore, I re-estimate (14) using a corrected measure of physical TFP that uses energy consumption as a proxy for capital stock. As can be seen from the third column of Table 7, the estimated coefficient on quality is now smaller, but still positive and statistically significant.

\footnotetext{
${ }^{20}$ The authors suggest a dynamic explanation for demand shifts that emphasizes the role of learning. An important difference with the current study is that consumers' knowledge accumulation process is exogenous to the producer, such that all firms benefit from the same growth rate of demand over time. Since the current paper emphasizes the endogenous nature of quality and the contemporaneous relationship between quality and production costs, but is silent on the intertemporal accumulation of brand capital, the two studies are complementary.

${ }^{21}$ Regions are defined according to the Bureau of Economic Analysis' definition of Labor Market Areas. Labor market areas are collections of counties that are usually, but not always, centered on Metropolitan Statistical Areas. See U.S. Bureau of Economic Analysis (1995) for detailed information. This measure of economic geography is superior to political divisions such as states or counties since it is based on commuting patterns. It therefore better captures the economic interactions between groups of producers and consumers. Since plant age cannot be measured accurately in the sample, observations are divided into categories according to the number of Censuses in which they appear. The age is determined using information from Census years 1963, 1967, 1972, 1977, 1982, 1987, 1992, and 1997.
} 


\section{Conclusion}

The firm heterogeneity literature argues that more productive firms self-select into the export market. However, selection is based on profitability, not productivity. In this paper I take a closer look at firm profitability and how it shapes price and export status patterns. I develop and estimate a model of international trade that separately identifies product quality and technical efficiency. The framework provides a tractable tool for studying the determinant of prices and export status.

I use the theory as a guide to construct a new plant-level proxy for product quality using price and quantity information. Intuitively, quality is defined as the ability to sell large quantities of output conditional on price. I use these plant-level measures of quality to study the determinants of variation in price and export status. The empirical results show that prices are increasing in product quality and decreasing in plant efficiency. I also find that exporters produce goods of higher quality on average but that selection into exporting is driven by the firm's ability to generate demand for its product, not by increases in efficiency. This result is inconsistent with the benchmark quality model. According to the model, increases in quality and efficiency both raise revenue and increase the probability of export. I show that relaxing the standard iceberg trade cost formulation standard in the literature helps reconcile the theory with the data. In the presence of per unit transport costs, distinguishing between quality and efficiency matters. This happens because per unit transport costs lead to a greater percentage change in price for low quality varieties.

Finally, it is important to emphasize the importance of the main results presented in this study. First, export status and aggregate factors explain about half of the variation in demand across manufacturing plants in my sample. Since it is difficult to argue that the other half is random, this implies that our current models are missing crucial components of producer behavior. Second, independent of their interpretation, the estimated demand shifts explain a large fraction of within industry changes in price and unit costs, especially in differentiated product categories. Further, these demand shifts are positively related to the plant's export status. Overall, these results bring to the fore the importance of plant-specific demand shifts and call for additional study of their determinants.

\section{REFERENCES}

Alchian, A. and W. Allen (1964). University economics. Wadsworth Publishing Company. 
Aw, B., G. Batra, and M. Roberts (2001). Firm heterogeneity and export-domestic price differentials: A study of Taiwanese electronics products. Journal of International Economics 54(1), 149-169.

Baldwin, R. and J. Harrigan (2010). Zeros, quality and space: Trade theory and trade evidence. American Economic Journal: Microeconomics (forthcoming).

Baldwin, R. and T. Ito (2007). Quality competition versus price competition goods: An empirical classification. NBER Working Paper No. 13214.

Basu, S., J. Fernald, and M. Kimball (2006). Are technology improvements contractionary? American Economic Review 96(5), 1418-1448.

Bernard, A. and J. Jensen (1995). Exporters, jobs, and wages in US manufacturing: 1976-1987. Brookings Papers on Economic Activity. Microeconomics, 67-119.

Bernard, A., J. Jensen, S. Redding, and P. Schott (2007). Firms in international trade. Journal of Economic Perspectives 21(3), 105-130.

Brooks, E. (2006). Why don't firms export more? Product quality and Colombian plants. Journal of Development Economics 80(1), 160-178.

Burnside, A., M. Eichenbaum, and S. Rebelo (1996). Sectoral Solow residuals. European Economic Review 40(3-5), 861-869.

Census (1996). Numerical List of Manufactured and Mineral Products. Reference Series, U.S. Census Bureau.

Crozet, M., K. Head, and T. Mayer (2008). Quality sorting and trade: Firm-level evidence for French wine. mimeo, University of Reims.

De Loecker, J. (2007). Product differentiation, multi-product firms and estimating the impact of trade liberalization on productivity. NBER working paper No. 13155.

Deaton, A. (1988). Quality, quantity, and spatial variation of price. American Economic Review, $418-430$.

Dixit, A. and J. Stiglitz (1977). Monopolistic competition and optimum product diversity. American Economic Review, 297-308.

Efron, B. and R. Tibshirani (1986). Bootstrap methods for standard errors, confidence intervals, and other measures of statistical accuracy. Statistical science 1(1), 54-77.

Faruq, H. (2006). New evidence on product quality and trade. CAEPR Working Paper No. 2006019.

Feenstra, R. (1988). Quality change under trade restraints in Japanese autos. Quarterly Journal of Economics, 131-146.

Foster, L., J. Haltiwanger, and C. Syverson (2008a). Reallocation, firm turnover, and efficiency: Selection on productivity or profitability? American Economic Review 98(1), 394-425.

Foster, L., J. Haltiwanger, and C. Syverson (2008b). The slow growth of new plants: Learning about demand. University of Maryland, Mimeo.

Grossman, G. and E. Helpman (1991). Quality ladders in the theory of growth. Review of Economic 
Studies, 43-61.

Hallak, J. and P. Schott (2010). Estimating cross-country differences in product quality. Quarterly Journal of Economics (forthcoming).

Hallak, J. and J. Sivadasan (2009). Firms's Exporting Behavior under Quality Constraints. NBER Working Paper No.14928.

Helble, M. and T. Okubo (2006). Heterogeneous quality and trade costs. Graduate Institute of International Studies Working Paper.

Hovland, M., J. Gauthier, and W. Micarelli (2000). History of the 1997 Economic Census. US Census Bureau.

Hummels, D. and P. Klenow (2005). The variety and quality of a nation's exports. American Economic Review, 704-723.

Hummels, D. and A. Skiba (2004). Shipping the good apples out? An empirical confirmation of the Alchian-Allen conjecture. Journal of Political Economy 112(6), 1384-1402.

Iacovone, L. and B. Javorcik (2010). Getting ready: Preparation for Exporting. University of Oxford, Mimeo.

Johnson, R. (2010). Trade and prices with heterogeneous firms. Dartmouth College, Mimeo.

Khandelwal, A. (2010). The long and short (of) quality ladders. Review of Economic Studies 77(4), 1450-1476.

Kneller, R. and Z. Yu (2008). Quality selection, Chinese exports and theories of heterogeneous firm trade. Columbia Business School, Mimeo.

Krugman, P. (1980). Scale economies, product differentiation, and the pattern of trade. American Economic Review, 950-959.

Kugler, M. and E. Verhoogen (2010). Prices, Plant size, and Product Quality. Review of Economic Studies (forthcoming).

Mandel, B. (2008). Heterogeneous firms and import quality: Evidence from transaction-level prices. University of California at Davis, Mimeo.

Manova, K. and Z. Zhang (2009). Export prices and heterogeneous firm models. Stanford University, Mimeo.

Melitz, M. (2003). The impact of trade on intra-industry reallocations and aggregate industry productivity. Econometrica, 1695-1725.

Rauch, J. (1999). Networks versus markets in international trade. Journal of International Economics 48(1), 7-35.

Roberts, M. and D. Supina (1996). Output price, markups, and producer size. European Economic Review 40(3-5), 909-921.

Roberts, M. and D. Supina (2000). Output price and markup dispersion in micro data: The roles of producer heterogeneity and noise. Advances in Applied Microeconomics: A Research Annual 9, $1-36$.

Roberts, M. and J. Tybout (1997). The decision to export in Colombia: an empirical model of entry 
with sunk costs. American Economic Review, 545-564.

Samuelson, P. (1952). The transfer problem and transport costs: the terms of trade when impediments are absent. Economic Journal, 278-304.

Schott, P. (2004). Across-product versus within-product specialization in international trade. Quarterly Journal of Economics 119(2), 647-678.

Staiger, D. and J. Stock (1997). Instrumental variables regression with weak instruments. Econometrica: Journal of the Econometric Society, 557-586.

Sutton, J. (1991). Sunk costs and market structure: Price competition, advertising, and the evolution of concentration. The MIT Press.

Sutton, J. and H. Street (2007). Quality, trade and the moving window: The globalization process. Economic Journal 117(524), F469-F498.

Syverson, C. (2004). Market structure and productivity: A concrete example. Journal of Political Economy 112(6), 1181-1222.

Verhoogen, E. (2008). Trade, quality upgrading, and wage inequality in the Mexican manufacturing sector. Quarterly Journal of Economics 123(2), 489-530.

Wooldridge, J. (2002). Econometric analysis of cross section and panel data. The MIT press.

\section{APPENDIX}

The following table lists the codes and description of the 143 five-digit product classes include in the sample. The superscript $d$ indicates products classified as differentiated.

Five Digit SiC Product Codes And Descriptions

\begin{tabular}{|c|c|c|c|}
\hline $\mathrm{SIC}$ & Name & $\mathrm{SIC}$ & Name \\
\hline 20111 & Beef, not Canned or made into Sausage & 23230 & Men's and Boy's Neckwear ${ }^{d}$ \\
\hline 20114 & Pork, not Canned or made into Sausage & 23532 & Cloth Hats and Caps ${ }^{d}$ \\
\hline 20136 & Pork, Processed or Cured & 23871 & Leather Belts $^{d}$ \\
\hline 20137 & Sausage and Similar Products, not Canned & 23872 & Belts other than Leather ${ }^{d}$ \\
\hline 2013B & Other Processed Meats & 24211 & Hardwood Lumber ${ }^{d}$ \\
\hline 20151 & Young Chickens & 24212 & Softwood Lumber ${ }^{d}$ \\
\hline 20153 & Turkeys & 24217 & Softwood Cut Stock ${ }^{d}$ \\
\hline 20159 & Liquid, Dried, and Frozen Eggs & 24261 & Hardwood Flooring $^{d}$ \\
\hline 20223 & Natural Cheese & 24262 & Hardwood Dimension Stock ${ }^{d}$ \\
\hline 20235 & Dry Milk Products & 24311 & Wood Window Units ${ }^{d}$ \\
\hline 20352 & Pickles and other Pickled Products ${ }^{d}$ & 24364 & Softwood Veneer \\
\hline 20353 & Prepared Sauces ${ }^{d}$ & 24365 & Softwood Plywood \\
\hline 20354 & Mayonnaise and Salad Dressings ${ }^{d}$ & 24390 & Fabricated Structural Wood Product \\
\hline 20372 & Frozen Vegetables & 24511 & Manufactured Mobile Homes ${ }^{d}$ \\
\hline 20382 & Frozen Dinners $^{d}$ & 24931 & Particleboard \\
\hline 20384 & Frozen Specialties $^{d}$ & 24937 & Prefinished Particleboard \\
\hline 20224 & Process Cheese and Related Products & 24266 & Wood Furniture Frames \\
\hline
\end{tabular}


Wheat Flour

20440 Milled Rice

20473 Dog Food

20481 Chicken and Turkey Feed

20482 Dairy Cattle Feed

20483 Dairy Cattle Feed Supplements

20485 Swine Feed Supplements

20487

20511

20512

20514

20521

20530

20610

20680

20771

20772

20791

20871

20910

20922

20923

20925

20951

20961

20962

20970

20980

$2099 \mathrm{E}$

2099G

$2221 \mathrm{C}$

$2221 \mathrm{D}$

22411

22516

22522

22571

22573

22581

22584

22617

22619

22628

22629

22690

22732

22811

22814

22825

22971

22982

22995
Beef Cattle Feed Supplements

Bread $^{d}$

Rolls, Bread-Type ${ }^{d}$

Soft Cakes ${ }^{d}$

Crackers, Pretzels, and Biscuits ${ }^{d}$

Frozen Bakery Products ${ }^{d}$

Sugarcane Mill Products

Nuts and Seeds

Grease and inedible Tallow

Feed and Fertilizer Byproducts

Shortening and Cooking Oils

Flavoring Extracts ${ }^{d}$

Canned and Cured Fish and Seafoods

Prepared Fresh Fish and Fresh Seafood ${ }^{d}$

Frozen Fish $^{d}$

Frozen Shellfish $^{d}$

Roasted Coffee $^{d}$

Potato Chips and Sticks ${ }^{d}$

Corn Chips and Related Products ${ }^{d}$

Manufactured Ice ${ }^{d}$

Macaroni, Spaghetti, and Egg Noodle ${ }^{d}$

Spices $^{d}$

Food Preparations

$85 \%$ or more Filament Fabrics

$85 \%$ or more Spun Yarn Fabrics

Woven Narrow Fabrics ${ }^{d}$

Women's Finished Panty Hose ${ }^{d}$

Men's Finished Seamless Hosiery ${ }^{d}$

Weft Knit Fabrics Greige Goods ${ }^{d}$

Finished Weft Knit Fabrics ${ }^{d}$

Warp Knit Fabrics Greige Goods ${ }^{d}$

Finished Warp Knit Fabrics ${ }^{d}$

Finished Cotton Broadwoven Fabrics

Finishing of Cotton Broadwoven Fabrics

Finished Manmade Fiber and Silk Fabrics

Finishing of Manmade Fabrics

Finished Yarn

Tufted Carpets and Rugs ${ }^{d}$

Carded Cotton Yarns

Spun Noncellulosic Fiber and Silk Yarns

Filament Yarns

Nonwoven Fabrics ${ }^{d}$

Soft Fiber Cordage and Twine ${ }^{d}$

Paddings and Upholstery Filling ${ }^{d}$
25113

25115

25120

25147

25151

26214

26314

26530

26552

26570

26732

26741

26742

26753

28430

28750

28917

28932

28934

29111

29920

31430

31440

31490

31610

31710

31720

32410

32730

32740

32751

33212

33219

33240

33417

33532

33541

33630

33640

34481

34494

34625

34996

35853

37322

37323

37324

37327

37921

39951
Wood Dining Room and Kitchen Furniture

Wood Bedroom Furniture

Upholstered Wood Household Furniture

Other Metal Household Furniture ${ }^{d}$

Innerspring Mattresses ${ }^{d}$

Uncoated Free sheet

Recycled Paperboard

Corrugated and Solid Fiber Boxes

Fiber Cans

Folding Paperboard Boxes

Specialty Bags and Liners ${ }^{d}$

Grocers Bags and Sacks

Shipping Sacks and Multiwall Bags

Surface-Coated Paperboard ${ }^{d}$

Surfactants and Finishing Agents ${ }^{d}$

Mixed Fertilizers

Nonstructural Caulking Compounds

Lithographic and offset Inks ${ }^{d}$

Flexographic Inks ${ }^{d}$

Gasoline

Lubricating Oils and Greases

Men's Footwear (except Athletic) ${ }^{d}$

Women's Footwear (except Athletic) ${ }^{d}$

Footwear (except Rubber) ${ }^{d}$

Suitcases $^{d}$

Handbags and Purses ${ }^{d}$

Personal Leather Goods ${ }^{d}$

Cement, Hydraulic

Ready-Mixed Concrete ${ }^{d}$

Lime

Gypsum Building Materials ${ }^{d}$

Other Ductile Iron Castings ${ }^{d}$

Other Gray Iron Castings ${ }^{d}$

Steel Investment Castings

Aluminum ingot

Aluminum Sheet and Strip

Extruded Aluminum Rod

Aluminum Die-Castings

Nonferrous Die-Castings

Prefabricated Metal Building Systems ${ }^{d}$

Fabricated Bar Joists ${ }^{d}$

Hot Impression Die Impact

Powder Metallurgy Parts ${ }^{d}$

Commercial Refrigerators ${ }^{d}$

Outboard Motorboats $^{d}$

Inboard Motorboats $^{d}$

Inboard-Outdrive Boats ${ }^{d}$

Other Boats ${ }^{d}$

Travel Trailers ${ }^{d}$

Metal Caskets and Coffins ${ }^{d}$ 